\title{
EFEITOS DA SOLARIZAÇÃO DO SOLO NA DENSIDADE POPULACIONAL DA TIRIRICA E NA PRODUTIVIDADE DE HORTALIÇAS SOB MANEJO ORGÂNICO'
}

\author{
MARTA DOS SANTOS FREIRE RICCI², DEJAIR LOPES DE ALMEIDA², MARIA DO CARMO ARAÚJO FERNANDES ${ }^{3}$, \\ RAUL DE LUCENA DUARTE RIBEIRO ${ }^{4}$ e MARIA CLÁUDIA DOS SANTOS CANTANHEIDE 5
}

\begin{abstract}
RESUMO - Foi conduzido um ensaio de campo em Seropédica, Estado do Rio de Janeiro, para avaliar o efeito da solarização do solo na população infestante de tiririca (Cyperus rotundus) e na produtividade de hortaliças submetidas a manejo orgânico. A solarização correspondeu à cobertura do solo com polietileno transparente $(50 \mu \mathrm{m})$ por um período de 210 dias. Houve um aumento da temperatura média da camada superficial do solo $(0-10 \mathrm{~cm})$ da ordem de $23 \%$, em relação ao das parcelas nãosolarizadas. Após a retirada do plástico, cultivaram-se: cenoura (Daucus carota 'Brasília'), repolho (Brassica oleracea var. capitata 'Astrus'), beterraba (Beta vulgaris 'Tall Top Early Wonder') e vagemanã (Phaseolus vulgaris 'Alessa'). Em termos gerais, a solarização reduziu em 59\% a reinfestação pela tiririca. Nas parcelas solarizadas, houve significativo incremento das produtividades de cenoura (28\%), vagem (32\%), beterraba (37\%) e repolho (34\%). A fixação biológica do nitrogênio, a julgar pela nodulação da vagem, não foi afetada pela solarização, mas a população de nematóides do solo sofreu considerável redução.

Termos para indexação: Cyperus rotundus, controle de ervas daninhas, tratamento térmico do solo, fixação de nitrogênio, nematóides.
\end{abstract}

\section{EFFECTS OF SOIL SOLARIZATION ON PURPLE NUTSEDGE POPULATION DENSITY AND ON PRODUCTIVITY OF VEGETABLE CROPS UNDER ORGANIC CULTIVATION}

\begin{abstract}
A field experiment was carried out at Seropédica, state of Rio de Janeiro, Brazil, to evaluate the effects of soil solarization on purple nutsedge (Cyperus rotundus) weed population and on productivity of vegetable crops under organic cultivation. Solarization was accomplished by covering the soil surface with transparent polyethylene sheets $(50 \mu \mathrm{m})$ for a period of 210 days. The mean temperature at $0-10 \mathrm{~cm}$ soil layer was about $23 \%$ higher than that of unsolarized plots. Following plastic removal the area was planted with carrot (Daucus carota 'Brasília'), cabbage (Brassica oleracea var. capitata 'Astrus'), garden beet (Beta vulgaris 'Tall Top Early Wonder'), and dwarf greenbean (Phaseolus vulgaris 'Alessa'). In general, soil solarization reduced purple nutsedge population by $59 \%$. There was a significant increase in yields of carrot (28\%), cabbage (34\%), beet (37\%), and greenbean $(32 \%)$ when compared to unsolarized plots. Biological nitrogen fixation, as judged by greenbean nodulation, was not affected by solarization but the soil nematode population was considerably reduced.

Index terms: Cyperus rotundus, weed control, soil heating, nitrogen fixation, nematode.
\end{abstract}

${ }^{1}$ Aceito para publicação em 4 de abril de 2000.

Trabalho integrante da Rede Agroecologia Rio (RECOPE) com apoio da FAPERJ e da FINEP.

${ }^{2}$ Eng. Agrôn., Dr., Embrapa-Centro Nacional de Pesquisa de Agrobiologia (CNPAB), antiga Rod. Rio-São Paulo, km 47, CEP 23851-970 Seropédica, RJ.

E-mail: marta@cnpab.embrapa.br

${ }^{3}$ Biól., Dr., PESAGRO-Rio, antiga Rod. Rio-São Paulo, km 47, CEP 23851-970 Seropédica, RJ.

E-mail: mcarmo@ rio.com.br

${ }^{4}$ Eng. Agrôn., Ph.D., Prof. Adjunto, Dep. de Entomologia e Fitopatologia, Universidade Federal Rural do Rio de Janeiro (UFRRJ), antiga Rod. Rio-São Paulo, km 47, CEP 23851-970 Seropédica, RJ.

${ }^{5}$ Biól.

\section{INTRODUÇÃO}

A tiririca (Cyperus rotundus L.) é uma herbácea perene, que se multiplica por sementes, e, vegetativamente, a partir de rizomas, bulbos e tubérculos subterrâneos. É considerada uma das espécies botânicas de maior amplitude de distribuição geográfica; está presente em praticamente todos os países de clima tropical ou subtropical, e, até mesmo, em regiões de clima temperado. No Brasil, é registrada em toda a extensão territorial. Tem grande capacidade de reprodução, podendo produzir cerca de 40 toneladas de massa verde por hectare. As raízes são fibrosas e finas, chegando a $1 \mathrm{~m}$ de profundidade $\mathrm{e}$ 
suportando períodos secos consideravelmente prolongados (Kissmann, 1991).

A solarização é uma alternativa física para desinfestação do solo, que consiste em cobri-lo, após umedecido, com um lençol de plástico transparente, assim permanecendo durante meses de intensa radiação solar e altas temperaturas, sendo, portanto, processo definido como hidrotérmico (Katan, 1981; Katan et al., 1983; Katan \& Vay, 1991). A umidade do solo é importante para a eficiência do tratamento, pois contribui para a condução do calor, inativando ou inibindo o crescimento de fitopatógenos e de propágulos de plantas tidas como daninhas (Souza, 1993; Ghini, 1997). Assim, durante a solarização, a temperatura do solo chega a atingir níveis letais (Katan et al.,1976; Katan, 1980, 1981; Ghini, 1991; Bettiol et al.,1996), além de provocar complexas alterações nas propriedades físicas, químicas e biológicas do solo, o que redunda em ganhos no rendimento das culturas (Vay, 1991).

A solarização tem-se mostrado eficiente no controle de ervas invasoras de diferentes gêneros (Katan, 1981). Porém, para a espécie $C$. rotundus, esse controle é apenas parcial (Elmore, 1991). Ricci et al. (1997) constataram, nos 30 dias iniciais do cultivo de cenoura em canteiros pré-solarizados, uma redução de $50 \%$ na população de tiririca.

O presente trabalho objetivou avaliar os efeitos da solarização do solo sobre a população reinfestante de tiririca e sobre a produtividade de quatro hortaliças submetidas a manejo orgânico.

\section{MATERIAL E MÉTODOS}

O ensaio foi conduzido na "Fazendinha Agroecológica Km 47", situada no Município de Seropédica, Estado do Rio de Janeiro $\left(22^{0} 45^{\prime} \mathrm{S}\right.$ de latitude e $43^{\circ} 45^{\prime} \mathrm{W}$ de longitude, a $33 \mathrm{~m}$ de altitude), e pertencente ao Sistema Integrado de Produção Agroecológica (SIPA). O solo da área experimental é um Planossolo arenoso, de acordo com a classificação da FAO/Unesco, tendo as seguintes características: $\mathrm{pH}$ 6,0 (água); $\mathrm{P}\left(74 \mathrm{mg} \mathrm{dm}^{-3}\right) ; \mathrm{K}\left(5,9 \mathrm{mmol}_{\mathrm{c}} \mathrm{dm}^{-3}\right) ; \mathrm{Ca}\left(34 \mathrm{mmol}_{\mathrm{c}} \mathrm{dm}^{-3}\right)$; $\mathrm{Mg}\left(17 \mathrm{mmol}_{\mathrm{c}} \mathrm{dm}^{-3}\right) ; \mathrm{Al}\left(0,0 \mathrm{mmol}_{\mathrm{c}} \mathrm{dm}^{-3}\right) ; \mathrm{C}$ orgânico $\left(7,7 \mathrm{~g} \mathrm{~kg}^{-1}\right)$ e $\mathrm{N}\left(0,87 \mathrm{~g} \mathrm{~kg}^{-1}\right)$. Não foram usados pesticidas, herbicidas ou fertilizantes industriais de alta solubilidade, visto que o SIPA destina-se a pesquisas sobre sistemas de produção em agricultura orgânica.

A área escolhida encontrava-se intensamente infestada pela tiririca e por outras espécies de ocorrência esparsa, tais como: colonião (Panicum maximum), caruru (Amaranthus retroflexus), picão-preto (Bidens pilosa), trapoeraba (Commelina banghalensis), capim-pé-de-galinha (Eleusine indica), salsa-serralha (Emilia sonchifolia), leiteira ou amendoim-bravo (Euphorbia heterophylla), carrapicho (Cenchrus echinatus), grama-seda ou bermuda (Cynodon dactylon) e beldroega (Portulaca oleracea).

O estudo foi constituído de duas fases. Na primeira, avaliaram-se parcelas solarizadas e não-solarizadas, num experimento em blocos casualizados com oito repetições. O solo foi coberto com filme de polietileno transparente (50 $\mu \mathrm{m}$ de espessura) durante 210 dias (outubro de 1997 a maio de 1998). As parcelas tinham $9,0 \mathrm{~m}$ de comprimento por 3,2 m de largura e a população infestante de tiririca foi avaliada a intervalos de 15 dias, por um período de 85 dias. As amostras foram coletadas em quadrantes de $0,5 \times 0,5 \mathrm{~m}$ dispostos ao acaso em três pontos de cada parcela. A segunda fase iniciou-se após a remoção da cobertura plástica e se estendeu pelo período compreendido entre junho e agosto de 1998, com o objetivo de estimar a capacidade de reinfestação da tiririca e o efeito da solarização sobre componentes da produtividade de hortaliças sob cultivo orgânico. Foram plantadas quatro hortaliças em canteiros medindo $4,50 \mathrm{~m}$ de comprimento por $1,20 \mathrm{~m}$ de largura, distribuídos nas parcelas originais. As hortaliças foram as seguintes: cenoura (Daucus carota 'Brasília'), repolho (Brassica oleracea var. capitata 'Astrus'), beterraba (Beta vulgaris 'Tall Top Early Wonder') e vagem-anã (Phaseolus vulgaris 'Alessa').

As mudas de repolho e beterraba foram produzidas em bandejas de poliestireno expandido (isopor) de 200 "células", abastecidas com substrato orgânico, e mantidas em casa de vegetação. O transplantio dessas mudas para os canteiros experimentais foi efetuado no mesmo dia da semeadura direta da cenoura e da vagem. Os espaçamentos adotados (em metros) foram de $0,25 \times 0,05 ; 0,50 \times 0,15$; $0,25 \times 0,10$ e $0,80 \times 0,40$, para cenoura, vagem, beterraba e repolho, respectivamente. Foi feita uma adubação pré-plantio de 20 t/ha de esterco bovino, em todos os canteiros, e o repolho recebeu complementação de $200 \mathrm{~g}$ de cama de aviário por planta, 25 dias após o transplantio das mudas.

Durante o ciclo das culturas foram feitas três capinas manuais nos canteiros, excetuando-se nos quadrantes de $0,5 \mathrm{~m}^{2}$, onde foram avaliadas as reinfestações de tiririca, mediante amostras coletadas aos 10, 25, 40 e 55 dias do plantio das hortaliças.

Os dados obtidos foram estatisticamente analisados como um fatorial de 2 (solarização) x 4 (hortaliça) x 4 (época de amostragem). Com referência às culturas, foram considerados os seguintes parâmetros: cenoura e beterraba - matéria fresca da folhagem e das raízes recém-colhidas -; repolho - peso das "cabeças" no ponto de colheita -; e vagem-anã - matéria seca da parte aérea (após colheita das vagens), número e matéria seca dos nódulos radiculares de rizóbio, número e peso das vagens verdes nas respectivas colheitas. 
Imediatamente após a retirada da cobertura de plástico, avaliou-se a população de nematóides presentes no solo, pelo método clássico de flutuação centrífuga em solução de sacarose (Jenkins, 1964). As suspensões resultantes foram submetidas a banho-maria $\left(50^{\circ} \mathrm{C}\right)$, e os nematóides, fixados em formalina a $4 \%$. Determinou-se o número total de nematóides recuperados, separados em dois grupos: os fitoparasitas, e os de vida livre (saprófitas), utilizando-se lâminas de Peters, com capacidade de $1 \mathrm{~mL}$, para as contagens.

\section{RESULTADOS E DISCUSSÃO}

Durante a fase de solarização, as temperaturas médias da camada superficial do solo $(0-10 \mathrm{~cm})$ foram de $49,7^{\circ} \mathrm{C}$ e de $40,4^{\circ} \mathrm{C}$ nas parcelas solarizadas e não-solarizadas, respectivamente, representando uma diferença de ordem de $23 \%$. A tiririca apresentou-se muito agressiva, com aumento acelerado da população, em seguida à preparação do solo (aração e gradagem). Ầ medida que outras espécies espontâneas surgiram, a população de tiririca diminuiu, provavelmente pelo sombreamento e competição exercidos. A densidade populacional média da tiririca nas parcelas solarizadas foi de 2,4 plantas $/ \mathrm{m}^{2}$ contra 964 plantas $/ \mathrm{m}^{2}$ nas parcelas não-solarizadas (Tabela 1). Este valor encontrado nas parcelas solarizadas correspondeu a algumas plantas que conseguiram ultrapassar o plástico.

A reinfestação das parcelas cultivadas com as hortaliças foi avaliada durante os primeiros 55 dias a partir dos plantios, representando cerca de $55 \%$ dos ciclos da cenoura e da beterraba, e cerca de $78 \%$ dos ciclos do repolho e da vagem. A população de tiririca cresceu até a terceira época de amostragem (42 dias). $\mathrm{Na}$ quarta e última amostragem (55 dias), verificouse redução em todas as parcelas cultivadas,

TABELA 1. Influência da solarização do solo na população infestante de tiririca (Cyperus rotundus), segundo diferentes épocas de amostragem (Seropédica, RJ, 1998) ${ }^{1}$.

\begin{tabular}{|c|c|c|c|c|c|c|}
\hline \multirow{2}{*}{$\begin{array}{l}\text { Tratamento do } \\
\text { solo } \\
\end{array}$} & \multicolumn{6}{|c|}{ Número de invasoras $/ \mathrm{m}^{2}$} \\
\hline & $15 \mathrm{DAS}^{2}$ & $30 \mathrm{DAS}$ & $45 \mathrm{DAS}$ & $70 \mathrm{DAS}$ & $85 \mathrm{DAS}$ & Média \\
\hline Solarizado $^{3}$ & $0 \mathrm{~b}$ & $8 \mathrm{~b}$ & $4 \mathrm{~b}$ & $\mathrm{Ob}$ & $\mathrm{Ob}$ & $2,4 \mathrm{~b}$ \\
\hline Não-solarizado & $956 \mathrm{a}$ & $1368 \mathrm{a}$ & $1152 \mathrm{a}$ & $788 \mathrm{a}$ & $556 \mathrm{a}$ & $964,0 \mathrm{a}$ \\
\hline
\end{tabular}

solarizadas ou não-solarizadas (Fig. 1). Esse declínio pode ser novamente explicado pelo sombreamento da tiririca pelas próprias hortaliças, bem como pelas outras invasoras, uma vez que nos quadrantes de amostragem nenhuma capina foi realizada.

A reinfestação de tiririca nas parcelas nãosolarizadas alcançou 1.151 plantas $/ \mathrm{m}^{2}$, contra 473 plantas $/ \mathrm{m}^{2}$ nas solarizadas. Cyperus rotundus tem sido considerada resistente ou moderadamente resistente à solarização do solo (Elmore, 1991). Os dados do trabalho, ora relatado, demonstraram que a solarização foi capaz de reduzir em 59\% a reinfestação média da tiririca nos canteiros cultivados com as hortaliças. Nos primeiros 10 dias de cultivo, houve redução da ordem de $80 \%$, de $60 \%$ após 25 dias; de 57\%, após 40 dias; e de 49\%, após 55 dias. De acordo com Rubin \& Benjamin (1984) e Elmore (1991), o controle apenas parcial da tiririca, pela solarização do solo, pode ser atribuído ao fato de que $5 \%$ dos tubérculos situados em profundidade maior que $30 \mathrm{~cm}$ são capazes de brotar ainda após o tratamento.

A solarização do solo influenciou o crescimento e a produtividade das hortaliças. No caso da cenoura, a colheita de raízes comercializáveis alcançou média de 36,5 t/ha contra 28,4 t/ha nas parcelas nãosolarizadas, o que representa um acréscimo de $28 \%$. Nas parcelas solarizadas e cultivadas com vagemanã ocorreu aumento de matéria seca da parte aérea, e produtividade mais elevada (número e peso de vagens verdes), esta última, superior em $32 \%$ (Tabela 2).

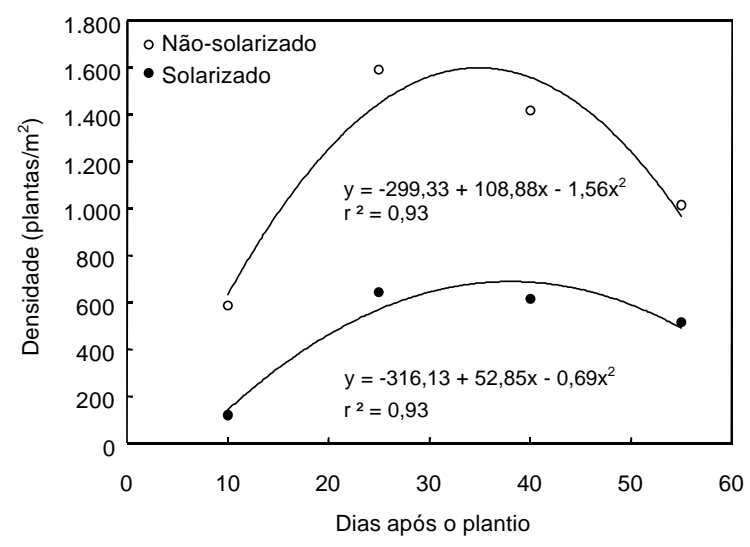

FIG. 1. Efeito da solarização do solo na reinfestação de tiririca (Cyperus rotundus) em cultivos orgânicos de hortaliças, segundo a época de amostragem (Seropédica, RJ, 1998). 
TABELA 2. Influência da pré-solarização do solo sobre o peso de matéria fresca da parte aérea e das raízes de cenoura, número e peso fresco de vagens, peso seco da parte aérea e número de nódulos de plantas de vagem-anã sob cultivo orgânico (Seropédica, RJ, 1998) ${ }^{1}$.

\begin{tabular}{lccccccc}
\hline \multirow{2}{*}{$\begin{array}{c}\text { Tratamento do } \\
\text { solo }\end{array}$} & \multicolumn{2}{c}{ Cenoura } & & \multicolumn{3}{c}{ Vagem-anã } \\
\cline { 2 - 3 } & $\begin{array}{c}\text { Parte aérea } \\
\text { (t/ha) }\end{array}$ & $\begin{array}{c}\text { Raízes } \\
(\mathrm{t} / \mathrm{ha})\end{array}$ & & $\begin{array}{c}\text { Número de } \\
\text { vagens } / \mathrm{m}^{2}\end{array}$ & $\begin{array}{c}\text { Peso das } \\
\text { vagens }(\mathrm{t} / \mathrm{ha})\end{array}$ & $\begin{array}{c}\text { Peso seco da parte } \\
\text { aérea }(\mathrm{g} / \mathrm{planta})\end{array}$ & $\begin{array}{c}\text { Número de } \\
\text { nódulos }\end{array}$ \\
\hline Pré-solarizado $^{2}$ & $12,0 \mathrm{a}$ & $36,5 \mathrm{a}$ & & $372 \mathrm{a}$ & $10,6 \mathrm{a}$ & $18,6 \mathrm{a}$ & $102 \mathrm{a}$ \\
Não-solarizado & $10,1 \mathrm{a}$ & $28,4 \mathrm{~b}$ & & $296 \mathrm{~b}$ & $8,0 \mathrm{~b}$ & $11,1 \mathrm{~b}$ & $90 \mathrm{a}$ \\
\hline $\mathrm{CV}(\%)$ & 27,2 & 19,1 & 9,7 & 17,7 & 16,1 & 56,8 \\
\hline
\end{tabular}

1 Os valores representam médias de oito repetições; médias seguidas da mesma letra não diferem entre si pelo teste $\mathrm{F}(\mathrm{p}<0,01)$.

2210 dias de cobertura com polietileno transparente (50 $\mu \mathrm{m}$ de espessura)

Analogamente, quanto à beterraba, a solarização influiu positivamente na produção de folhagem e de raízes comercializáveis, esta última superando em $37 \%$ a colheita das parcelas não-solarizadas. A produtividade do repolho foi também substancialmente incrementada, em decorrência da solarização, com uma diferença que chegou a $34 \%$ (Tabela 3 ).

O efeito benéfico da solarização sobre as culturas pode ser, em parte, atribuído a alterações nos componentes bióticos e abióticos do solo. Segundo Ghini \& Bettiol (1995), além da inativação parcial da tiririca e de outras invasoras, a solarização exerce um controle sobre fitoparasitas, e estimula populações de microrganismos antagonistas e de promotores de crescimento; promove, ainda, a disponibilização de nutrientes no solo, tais como: N (nas formas de amônia e nitrato), Ca e Mg, além de mudanças em sua composição gasosa, com a liberação de substâncias voláteis, melhoria da estrutura, e conseqüente penetração de umidade.

A simbiose com Rhizobium, avaliada pelo número e peso de nódulos presentes nas raízes de vagemanã, não foi influenciada pela solarização, o que confirma resultados anteriormente reportados (Ricci et al., 1997). A não-interferência no processo de fixação biológica do N é de especial importância em sistemas orgânicos de produção agrícola, nos quais o uso de fertilizantes industriais de alta solubilidade não é recomendado.

A solarização reduziu significativamente a população dos dois grupos de nematóides no solo, e constatou-se que os fitoparasitas foram mais sensíveis que os saprófitos (Tabela 4).
TABELA 3. Efeito da pré-solarização do solo sobre as produtividades de beterraba e repolho sob cultivo orgânico (Seropédica, RJ, 1998) ${ }^{1}$.

\begin{tabular}{lcccc}
\hline Tratamento do solo & \multicolumn{2}{c}{ Beterraba } & & Repolho \\
\cline { 2 - 3 } & $\begin{array}{c}\text { Parte aérea } \\
(\mathrm{t} / \mathrm{ha})\end{array}$ & $\begin{array}{c}\text { Raízes } \\
(\mathrm{t} / \mathrm{ha})\end{array}$ & & $\begin{array}{c}\text { "Cabeças" } \\
(\mathrm{t} / \mathrm{ha})\end{array}$ \\
\hline Pré-solarizado $^{2}$ & $26,2 \mathrm{a}$ & $30,6 \mathrm{a}$ & & $84,0 \mathrm{a}$ \\
Não-solarizado & $20,4 \mathrm{~b}$ & $22,3 \mathrm{~b}$ & $62,8 \mathrm{~b}$ \\
\hline $\mathrm{CV}(\%)$ & 15,5 & 20,8 & 21,1 \\
\hline 1 & Os valores representam médias de oito repetições; médias seguidas da \\
mesma letra não diferem entre si pelo teste de $\mathrm{F}(\mathrm{p}<0,01)$. \\
2
\end{tabular}

TABELA 4. Efeito da solarização do solo nas populações de nematóides fitoparasitos e saprófitas (Seropédica, RJ, 1998) ${ }^{1}$.

\begin{tabular}{lccc}
\hline Tratamento do solo & \multicolumn{3}{c}{ Número de nematóides recuperados } \\
\cline { 2 - 4 } & Saprófitas & Fitoparasitas & Média \\
\hline Pré-solarizado ${ }^{2}$ & $4,6 \mathrm{a}$ & $28,6 \mathrm{~b}$ & $16,6 \mathrm{~b}$ \\
Não-solarizado & $5,0 \mathrm{a}$ & $549,1 \mathrm{a}$ & $277,1 \mathrm{a}$ \\
\hline Média & $4,8 \mathrm{~b}$ & $288,9 \mathrm{a}$ & - \\
\hline & \multicolumn{3}{c}{ Os valores representam médias de oito repetições; médias seguidas da } \\
mesma letra não diferem entre si pelo teste de $\mathrm{F}(\mathrm{p}<0,01) ; \mathrm{CV}=55,3 \%$. \\
2 & 210 dias de cobertura com polietileno transparente $(50 \mu \mathrm{m}$ de espessura).
\end{tabular}

\section{CONCLUSÕES}

1. A solarização do solo com cobertura de polietileno exerce um controle parcial, porém altamente significativo, sobre a população infestante de C. rotundus.

2. A solarização reduz a reinfestação de tiririca.

3. As culturas de cenoura, repolho, beterraba e vagem-anã são significativamente mais produtivas quando cultivadas em parcelas pré-solarizadas. 
4. O processo de solarização não interfere na taxa de fixação biológica do nitrogênio, mas é capaz de reduzir consideravelmente a população de nematóides presentes no solo.

\section{REFERÊNCIAS}

BETTIOL, W.; GHINI, R.; CUNHA, M.I.B.; TRATCH, R.; GALVÃO, J.A.H. Solarização do solo para controle de nematóide das galhas em quiabeiro. Horticultura Brasileira, Brasília, v.14, p.158-160, 1996.

ELMORE, C.L. Weed control by solarization. In: KATAN, J.; VAY, J.E. de (Ed.). Soil solarization. Boca Raton : CRC, 1991. p.61-72.

GHINI, R. Desinfestação do solo com o uso de energia solar: solarização e coletor solar. Jaguariúna : Embrapa-CNPDA, 1997. 29p. (Embrapa-CNPDA. Circular, 1).

GHINI, R. Integração do controle biológico com outros métodos de controle de doenças de plantas. In: BETTIOL, W. (Org.). Controle biológico de doenças de plantas. Jaguariúna : Embrapa-CNPDA. 1991. 388p. (Embrapa-CNPDA. Documentos, 15).

GHINI, R.; BETTIOL, W. Controle físico. In: BERGAMIN FILHO, A.; KIMATI, H.; AMORIM, L. (Ed.). Manual de fitopatologia. 3.ed. São Paulo : Agronômica Ceres, 1995. p.786-803.

JENKINS, W.R. A rapid centrifugal-flotation technique for separating nematodes from soil. Plant Disease Reporter, St. Paul, v.48, p.692, 1964.

KATAN, J. Solar heating (solarization) of soil for control of soilborne pests. Annual Review of Phytopathology, Palo Alto, v.19, p.211-236, 1981.
KATAN, J. Solar pasteurization of soils for disease control: status and prospects. Plant Disease, St. Paul, v.64, p.450-454, 1980.

KATAN, J.; FISHLER, G.; GRINTEIN, A. Short-and longterm effects of soil solarization and crop sequence on Fusarium wilt and yield of cotton in Israel. Phytopathology, St. Paul, v.73, p.1215-1219, 1983.

KATAN, J.; GREENBERGER, A.; ALON, H.; GRINSTEIN, A. Solar heating by polyethylene mulching for the control of diseases caused by soilborne pathogens. Phytopathology, St. Paul, v.66, p.683-688, 1976.

KATAN, J.; VAY, J.E. de. Soil solarization: historical perspectives, principles, and uses. In: KATAN, J.; VAY, J.E. de (Ed.). Soil solarization. Boca Raton : CRC, 1991. p.23-37.

KISSMANN, K.G. Plantas infestantes e nocivas. São Paulo : BASF-Brasileira, 1991. t.1.

RICCI, M. dos S.F.; ALMEIDA, D.L. de; GUERRA, J.G.M. Efeito da solarização na população infestante de tiririca (Cyperus rotundus) e na produção de hortaliças. Seropédica : Embrapa-CNPAB, 1997. 5p. (Embrapa-CNPAB. Comunicado Técnico, 18).

RUBIN, B.; BENJAMIN, A. Solar heating of the soil: involvement of environmental factors in the weed control process. Weed Science, Champaign, v.32, p.138, 1984.

SOUZA, N.L. Controle de fitopatógenos do solo por solarização. In: SIMPÓSIO DE AGRICULTURA ECOLÓGICA, 1., 1993, Campinas. Anais. Campinas : Fundação Cargill, 1993. p.77-98.

VAY, J.E. de. Historical review and principles of soil solarization. In: INTERNATIONAL CONFERENCE ON SOIL SOLARIZATION, 1., 1990, Amman. Proceedings. Rome : FAO, 1991. p.1-11. 